\title{
Megaeventos e Unidades de Polícia Pacificadora: representações sobre o lugar das favelas no tecido urbano
}

\author{
Luis Claudio Palermo ${ }^{1}$ \\ Universidade do Estado do Rio de Janeiro (UERJ), Rio de Janeiro, Brasil \\ E-mail: luisclaudio72@gmail.com
}




\section{Resumo}

A implantação das Unidades de Polícia Pacificadora (UPPs) gerou grande visibilidade política ao governo do Estado do Rio de Janeiro, que passou a utilizar o projeto no sentido de sublinhar as características positivas e os aspectos de mudança, no que se refere às políticas de segurança nas favelas. Neste trabalho pretende-se colocar tal iniciativa em perspectiva crítica e mostrar outra dimensão das UPPs que se relaciona ao seu sentido de continuidade. Assim, utilizar-se-á uma fonte pouco conhecida e divulgada para estabelecer uma relação entre os megaeventos e a implantação das UPPs. A construção desse objeto, pois, propiciou colocar em discussão as representações das favelas e seus moradores, propondo outras interpretações sobre o referido projeto de segurança. Portanto, o artigo visa iluminar, utilizando-se de uma leitura crítica das fontes e com base na literatura científica sobre o tema, o que o projeto das UPPs guarda de continuidade na relação favela e cidade.

Palavras-chave: Representações Sociais. Favelas Cariocas. Unidades de Polícia Pacificadora.

\section{Abstract}

The deployment of the Unidades de Policia Pacificadora (UPP) has generated great political visibility to the state government of Rio de Janeiro. This started to use the project in order to emphasize the positive features and aspects of change with regard to security policies in the slums. We aim to put this in perspective critical discourse and show another dimension of the UPPS that relates to your sense of continuity. Thus, we used a little-known source and disclosed to establish a relationship between mega events and the implementation of UPPS. The construction of this object, therefore, allowed me to put in discussion the representations of the slums and its residents, proposing other interpretations on such security project. Therefore, this article aims to enlighten, using a critical reading of the sources and based on the scientific literature on the subject, what the UPP project keeps continuity in the relationship and city slums.

Keywords: Social Representations. Rio Slums. Unidades de Polícia Pacificadora. 


\section{Introdução}

A literatura clássica sobre as favelas cariocas coloca em evidência, dade e com o processo de modernização brasileiro, especialmente a partir dos anos de 1930 (Mendonça, 1986), quando elas proliferavam significativamente no cenário urbano (Silva, 2005) e seu controle tornava-se um ponto premente para os governos da época, como fica evidenciado, por exemplo, no Código de Obras de 1937, que, mesmo reconhecendo a existência das favelas, propugnava a eliminação delas (Burgos, 1998, p. 27). Dessa forma, o controle das favelas assumia uma dimensão territorial num tecido urbano cada vez mais valorizado e era considerado fundamental, pelo governo, o controle de sua expansão e da vida de seus moradores. (Parise, 1969; Leeds; Leeds, 1978; Valla, 1986; Burgos, 1998; Machado da Silva, 2002)

Em face do que foi amplamente discutido na literatura clássica, torna-se importante posicionar a discussão acerca das Unidades de Polícia Pacificadora (doravante denominadas UPPs) numa perspectiva histórica e crítica que enfoque no que o programa tem de continuidade, tendo como referência a produção da renomada literatura científica. Nesse sentido, apresentarei os objetivos das UPPs como um ponto basilar e inicial, para, em seguida, relacionar os megaeventos que a cidade do Rio de Janeiro sediará, especialmente, a Olimpíada de 2016, aos objetivos não declarados das UPPs, ou seja, a vigilância e o controle das favelas.

Não se pretende, obviamente, afirmar que o projeto se reduz ao controle e vigilância das novas "classes perigosas", mas o intuito é colocar em discussão essa dimensão para que se suscitem novos debates 
acerca das UPPs, transpassando os limites da euforia e das novidades do programa, pontos que devem ser reconhecidos, mas que não se configuram como foco da análise que farei aqui.

Propõe-se, portanto, primeiramente apresentar os objetivos das UPPs que são declarados aberta e transparentemente pelo governo. A partir dessa base, pretende-se elucidar como há outras finalidades não declaradas, ou não constantemente repisadas de forma clara, mas que contribuem efetivamente para a compreensão do programa e da relação entre favela e cidade em seu sentido sociológico e histórico. A finalidade que se deseja destacar é a da vigilância e controle das favelas "classes perigosas", não as excluindo, mas sim as mantendo sob o controle da ordem (Foucault, 2011), numa conjuntura em que a cidade do Rio de Janeiro e o Brasil aparecem "[...] com atrativas fronteiras urbanas exatamente em razão do ciclo de prosperidade e estabilidade que atravessamos". (Ribeiro, 2011, p. 4)

A exposição analítica feita neste trabalho está fundamentada, no tocante aos objetivos declarados pelo governo do Estado do Rio de Janeiro sobre as UPPs, na análise de conteúdo de matérias veiculadas no jornal $O$ Globo (Rondelli, 2000, p. 50). Este trabalho foi realizado tendo como delimitação temporal o período de 19 de novembro de 2008 até fevereiro de 2009, compreendendo a entrada dos policiais militares no Morro Santa Marta até a inauguração da segunda UPP, na Cidade de Deus, em 16 de fevereiro de 2009. A delimitação temporal dessas matérias justifica-se por ser o período de implantação das primeiras UPPs, o que suscitou discussões atinentes aos objetivos do projeto, na medida em que tal projeto foi se constituindo aos poucos, sem um corpo definitivo de critérios pré-formatados. Nesse sentido, segundo o próprio Secretário de Segurança, José Mariano Beltrame, o programa foi implantado como "[...] um laboratório, um modelo de política de segurança pública" (Jornal O Globo, 2008, p. 13). Convém aduzir que o critério de seleção das matérias analisadas foi baseado na escolha das que tinham relação direta com a preparação e instalação das UPPs do morro Santa Marta e que acionavam os objetivos declarados do novo projeto de segurança em favelas. 
Além das referidas matérias de jornal, selecionadas para discussão acerca do projeto das UPPs, escolheu-se como fonte bastante importante o Dossiê de Candidatura do Rio de Janeiro à Sede dos Jogos Olímpicos e Paraolímpicos de 2016, de forma a cotejar essa fonte com os discursos do governo divulgados em veículos de mídia, visando ampliar o olhar crítico sobre o que se foi dito, buscando o não dito.

Como parâmetro macro que serve para se pensar e discutir o projeto das UPPs, contemplando sua temporalidade desde sua implantação até o momento atual, utiliza-se como referência uma base de dados com a catalogação de todas as matérias sobre as UPPs que foram veiculadas no Jornal $O$ Dia, pesquisa realizada como prática rotineira de trabalho e análise do fenômeno sociológico, com a finalidade de compreender o programa.

Tanto na favela considerada modelo para o projeto das UPPs - a Santa Marta - como na Cidade de Deus - segunda favela a ser ocupada -, o programa foi construído no transcorrer de sua própria execução. O governo foi, portanto, paulatinamente adequando seu planejamento às necessidades práticas de implantação. Logo, os objetivos concernentes às UPPs sofreram ajustes para dar conta da melhor forma de implantação do projeto, o que não significa que não houvesse um sentido geral a ser seguido. Havia ideias e concepções teóricas já colocadas em prática em outros lugares e outras épocas, mas as UPPs foram sendo colocados em prática como um "laboratório".

\section{Objetivos das UPPs}

Não obstante algumas características laboratoriais das UPPs, observa-se elementos que podem ser considerados basilares que nasceram junto com o projeto e foram sendo lapidados, delineando a orientação geral do programa de segurança. Isso fica claro ao se analisar os objetivos declarados do programa, e são eles que se colocam em destaque neste ponto. Com efeito, tais elementos formam a base desse modelo de policiamento e se mantiveram como sustentáculos do projeto. Alguns deles constam das declarações dos próprios formuladores do programa, conforme a seguir: 
Vamos criar uma nova maneira de policiamento comunitário, com uma nova nomenclatura. Segurança pública não é somente ações policiais. Precisamos que o estado entre com os serviços. É importante que as pessoas tenham dignidade - disse José Mariano Beltrame. (Jornal O Globo, 2008, p. 12. grifos nossos)

Um novo modelo de policiamento seria criado no Morro Santa Marta, segundo palavras do Secretário de Segurança Pública, e esse modelo estaria fundamentado em dois pontos estruturadores: policiamento comunitário e, como consequência da presença da polícia, maior participação do Estado, oferecendo serviços aos moradores. As palavras do Governador Sérgio Cabral não deixam dúvidas quanto ao terceiro pilar declarado do projeto, ou seja, policiamento ostensivo e permanente, de forma a retomar o controle do território, conforme excerto a seguir:

Agentes da PF do Rio também confirmaram que os pontos de venda de drogas fecharam e os bandidos desapareceram do morro. Mas, segundo um delegado, ainda é cedo para comemorar:

- Temos que esperar um tempo para saber se a ação da PM atingiu também o cliente interno do traficante, que vive dentro da favela.

Cabral prefere não festejar

O governador Sérgio Cabral também demonstrou cautela. Perguntado se já é possível afirmar que o tráfico acabou no Morro Dona Marta, ele respondeu:

- Dá para afirmar que no Morro Dona Marta o nosso objetivo é esse. Como numa rua qualquer do asfalto do Rio, você tem que ter um policiamento permanente e a garantia da ordem. (Jornal O Globo, 2008, p. 13, grifos nossos)

Portanto, durante o período de ocupação da primeira favela que recebeu uma UPP - Santa Marta -, já foram explicitados os objetivos principais do projeto: (a) retomada do território controlado por traficantes de drogas; (b) implantação de um tipo de policiamento denominado de comunitário e com presença constante; (c) como consequência, a promoção de serviços sociais, com maciça atuação do Estado, propiciando a criação de uma nova relação entre Estado e 
favelas. Esses são os pontos que foram oficialmente tratados e que até hoje são colocados como objetivos primazes do projeto.

\section{Objetivos não Declarados das UPPs}

O projeto das UPPs, entretanto, não se circunscreveu apenas a esses objetivos, pois havia outros fios condutores e finalidades que não estavam explicitados. Aliás, é necessário destacar que tais finalidades não foram divulgadas até que o projeto se consolidasse, o que pode ser identificado a partir de 2011, mais de dois anos após a implantação da primeira UPP.

Não obstante o fato de especialistas e críticos terem pontuado e revelado outros objetivos implícitos do referido projeto, como, por exemplo, sua ligação com os megaeventos e a preparação da cidade como uma metrópole vendável (Ribeiro, 2011), esses objetivos somente foram postos em cena e acionados como discurso de segurança no momento em que o programa ganhou visibilidade expressiva e quando já desfrutava de expectativas positivas por parte da população.

Na medida em que os primeiros discursos governamentais que foram publicados na imprensa não contemplavam o os Jogos Olímpicos de 2016 nem a Copa do Mundo de 2014 como vetores que contribuíram para a concepção e implantação do novo modelo de policiamento em favelas, não é tarefa fácil perceber esta relação. Logo, para que se possa desvelar a relação entre os megaeventos e a implantação das UPPs, há que se investir em examinar os discursos não explicitados de forma patente e não amplamente divulgados em veículos de mídia e, nesse sentido, há que se colocar em cena novas fontes analíticas.

Selecionei para esta tarefa analítica e reflexiva o Dossiê de Candidatura do Rio de Janeiro à Sede dos Jogos Olímpicos e Paraolímpicos de 2016, documento importante, pouco divulgado para o grande público, bem como entre as pesquisas ligadas às UPPs. Evoco-o com o fito de ampliar a visão acerca dos objetivos tão propalados das UPPs, propondo uma discussão mais ampliada do projeto, visando compreender o que não foi significativa e patentemente dito. Segue um trecho que faz parte da introdução do terceiro volume do Dossiê, que é responsável pelo quesito referente à segurança dos Jogos: 
Os Jogos Olímpicos e Paraolímpicos Rio 2016 serão uma grande festa do esporte, que começará nas instalações e irá se espalhar pela cidade e pelo mundo. Uma celebração como essa só pode acontecer com a entrega impecável do evento. Por isso, enquanto o Rio de Janeiro estiver sediando um festival inesquecível, todos os aspectos técnicos vitais e os requisitos dos clientes dos Jogos estarão no centro das atenções.

O Comitê de Candidatura Rio 2016, trabalhando em conjunto com os três níveis de Governo, garante que essas necessidades serão totalmente atendidas, com base em um extenso planejamento apoiado nas mais diversas garantias que eliminarão todos os possíveis riscos.

A cidade do Rio de Janeiro possui ampla experiência na realização de grandes eventos, como o Carnaval, os grandes shows na praia de Copacabana ou os Jogos Panamericanos e Parapan-americanos Rio 2007. Todos esses eventos transcorreram e transcorrem com segurança, sendo extremamente bem sucedidos e repletos do mesmo espírito de celebração.

Os setores de acomodação, segurança e transportes vem se beneficiando das recentes melhorias em infraestrutura e, antes dos Jogos, novos investimentos da ordem de US\$ 5 bilhões garantirão uma estrutura sólida para a realização dos Jogos Olímpicos e Paraolímpicos. Por todas essas razões o Rio está pronto para receber o mundo de braços abertos, com os visitantes podendo aproveitar novos patamares de eficiência e confiabilidade. [...]

A segurança será abrangente, baseada na experiência do Rio de Janeiro. A abordagem será totalmente integrada com as iniciativas já existentes na área, incluindo os diversos programas para melhoria da segurança. (Comitê Olímpico Brasileiro, 2009 , p. 5, grifos nossos)

Nota-se, nessa introdução, uma preocupação centrada na segurança e nos riscos dos Jogos. Por isso, a linha expositiva baseia-se na experiência do Rio de Janeiro em realizar grandes eventos, bem como nos investimentos previstos para a construção de uma infraestrutura para a Olimpíada de 2016. Nesse sentido, são reveladores os planos de investimentos que constam do Dossiê.

No que se refere à "Melhoria dos sistemas de Treinamento da Polícia", os objetivos são: "Treinamentos especializados para a polícia no 
relacionamento com as comunidades carentes e na resolução de conflitos". (Comitê Olímpico Brasileiro, 2009, p. 28, grifos nossos)

Em relação ao "Aumento das tropas da Polícia Militar", os objetivos que constam do documento são: "Aumentar as tropas da Polícia Militar de 38.000 (atualmente) para 54.000 em 2012, para garantir uma presença policial permanente nas zonas de alto risco nas comunidades [considerando apenas os custos do treinamento]" (Comitê Olímpico Brasileiro, 2009, p. 28, ). Convém aduzir que o próprio Beltrame, em entrevista ao Jornal O Dia, perguntado se haveria novos concursos para a Polícia Militar, afirmou o seguinte: "Vamos aumentar o efetivo de 37 mil para 55 mil [policiais]. Isso, inclusive, é exigência do Comitê Olímpico para 2016". (Jornal O Dia, 2010)

Considerando-se o "Treinamento intensivo da Polícia Militar", cujo período de implantação está previsto para ser entre 2008 e 2016, há uma ligação concreta entre o Dossiê e a implantação do policiamento comunitário em favelas, ainda que não se faça efetivamente uma referência explícita às UPPs. Objetivos do treinamento:

Introdução de cursos especializados, incluindo:

1. Reação tática: incorporar o comando de incidente e o serviço de inteligência policial (2.000 participantes por ano)

2. Polícia comunitária e resolução de conflitos, incorporando o cuidado com os grupos vulneráveis.

e o treinamento dos oficiais de apoio comunitário (2.000 participantes por ano)

3. Cursos de inglês e espanhol ( 500 por ano). (Comitê Olímpico Brasileiro, 2009, p. 28, grifos nossos)

Não se deseja afirmar que o projeto das UPPs está fadado a ser desmobilizado com o fim das Olimpíadas de 2016, nem que vai continuar e ter sucesso. Não é esse o objetivo da argumentação que vem sendo proposta. O que se propõe está fundamentado na explicitação dos objetivos não declarados pelo governo nem pela imprensa como finalidades importantes para o projeto. E a relação com os megaeventos emerge com vigor, a partir do cotejamento entre objetivos das UPPs encontrados em declarações feitas em veículos de mídia e o Dossiê da Candidatura do Rio de Janeiro. 
Nesse caminho analítico-crítico, é revelador notar a relação que há entre algumas variáveis importantes que compõem o Projeto das UPPs e o Dossiê, notadamente no que concerne ao "Tema 13", que aborda o item "Segurança". Observa-se, portanto, em que medida pelo menos duas dentre as finalidades declaradas das UPPs têm relação direta com os objetivos explicitados no Dossiê para as Olimpíadas de 2016, a saber:

$\left(1^{\circ}\right)$ "polícia comunitária e resolução de conflitos, incorporando o cuidado com os grupos vulneráveis" (Comitê Olímpico Brasileiro, 2009, p. 28);

$\left(2^{\circ}\right)$ aumento do efetivo policial, ação que pode viabilizar a consequente ocupação da polícia nas favelas, pois:

A redução da criminalidade foi e continua sendo um dos principais objetivos das autoridades policiais no Rio de Janeiro. Iniciativas de combate ao crime são tomadas em conjunto com estratégias de redução da criminalidade nas comunidades. (Comitê Olímpico Brasileiro, 2009, p. 28, grifos nossos)

Ainda que o projeto das UPPs não conste explicitamente referido Dossiê, não se pode negar a relação entre a implantação do novo modelo de policiamento e os megaeventos. Conforme argumentado anteriormente, o próprio fato de a UPP ter sido um programa que foi se constituindo à medida que a ocupação foi sendo realizada, aprendendose com o dia a dia e constituindo-se como programa de policiamento na prática, reforça sua ligação com o que está enunciado no Dossiê e com a ausência da definição de uma proposta de implantação das UPPs neste documento oficial.

Ora, o fato de o Dossiê ter sido publicado em 2009 e a primeira UPP ter sido implantada no final do mês de dezembro de 2008 contribui ainda mais para se pensar tal relação, pois não há a necessidade de ser um gestor para saber que a construção de um Dossiê destinado a um evento desse porte e envergadura não pode ter sido resultado de poucos dias de labuta, muito menos que tenha sido elaborado sem a participação da equipe da Secretaria de Segurança do Estado do 
Rio de Janeiro, Sede da Olimpíada. Depreende-se, portanto, que sua concepção e formulação como documento-base da candidatura do Rio de Janeiro sucederam bem antes da implantação da primeira UPP, no Morro Santa Marta. Por essa linha de raciocínio, então, pode-se inferir que as UPPs guardam uma relação direta com o fato de o Rio de Janeiro ser sede de megaeventos, não obstante essa relação não tenha sido valorizada nem explicitada pelo governo e pelos veículos de mídia.

\section{Finalmente, o Reconhecimento da Relação Entre UPPs e os Megaeventos}

A assunção de um discurso voltado para a relação entre o projeto das UPPs e os megaeventos ocorreu a partir do anúncio da ocupação do Morro da Mangueira, com o objetivo de se promover a instalação de uma base que se transformaria em UPP. Esse discurso, no entanto, não foi diretamente colocado como parte dos objetivos primazes da implantação e expansão do projeto de policiamento comunitário. A repercussão do discurso governamental na imprensa apresentava-se como construção de um cinturão de segurança, o que não deixa de ser revelador no sentido da produção de um mecanismo de vigilância e controle de um lugar que representa aglomerados "subnormais" e que necessita de um "braço" do estado para manter seu controle. Esse poder ramificado do Estado é exercido pela polícia que, segundo Foucault, representa "[...] o conjunto dos meios pelos quais é possível fazer as forças do Estado crescerem, mantendo ao mesmo tempo a boa ordem desse Estado". (Foucault, 2008, p. 421)

A preparação que a polícia fez para a invasão e ocupação do morro da Mangueira gerou na imprensa notícias informando que, com a instalação desta UPP, o Governo completaria o cinturão de segurança do maciço da Tijuca, cujos equipamentos Olímpicos seriam de grande relevância para os megaeventos a serem realizados na cidade, como, por exemplo, o Complexo Esportivo do Maracanã. São apresentados alguns exemplos de divulgação midiática acerca da matéria em questão, fato que revela a concatenação entre as ações governamentais em favelas no sentido dos megaeventos e como se ainda opera com uma noção estigmatizada desses lugares de moradia. 
No dia 30 de maio de 2011, Ana Paula Araújo, apresentadora do programa RJ-TV ( $1^{\text {a }}$ edição), declarou que a próxima favela que seria ocupada era a da Mangueira, com vistas à criação de "[...] um cinturão de segurança no entorno do Maracanã [...]", obviamente em razão da Copa do Mundo de 2014 e da Olimpíada de 2016. A referida notícia foi confirmada, no mesmo dia pela Rádio CBN durante as intervenções do "Repórter $\mathrm{CBN}$ ", que apresenta as principais notícias que ocorrem na cidade e no país a cada meia hora.

O Jornal O Dia, dando destaque de página inteira à matéria, expôs a informação da seguinte forma: "Governo anuncia ação para instalar UPP na Mangueira". Como subtítulo estava escrito: "A nova unidade vai fechar o cinturão de segurança no entorno do Maracanã, palco da Copa do Mundo de 2014 e dos Jogos Olímpicos de 2016" (Jornal O Dia, 2011, p. 4). Ademais, na mesma edição do jornal, o Editorial de O Dia opinou sobre o fato, confirmando a ligação do programa com os megaeventos, no período da então instalação da UPP do morro da Mangueira:

Bem-sucedida, a implantação da UPP da Mangueira concluirá o cinturão de segurança no Grande Centro e em boa parte da Zona Norte - em especial nas cercanias do Maracanã, protagonista da cidade em 2014, por ocasião da Copa do Mundo, e em 2016, nas Olimpíadas. (Jornal O Dia, 2011, p. 18)

O Jornal Expresso também deixou clara a orientação do governo por meio de matéria publicada, em que afirma num trecho:

A $18^{a}$ Unidade de Polícia Pacificadora [a da Mangueira] fecha o cinturão de segurança criado pela ocupação de quase todas as favelas do Maciço da Tijuca (Turano, Salgueiro, Formiga, Andaraí, Borel, Macacos e São João), uma área importante para a segurança do Maracanã e Maracanãzinho. (Jornal Expresso, 2011, p. 3)

Em uma matéria veiculada no jornal $O$ Globo, fica bastante evidente a intenção espacial das UPPs e sua relação com os megaeventos, quando os repórteres - baseados em informações providas pela própria Secretaria de Segurança - afirmam que: 
[...] com o fechamento dessa região, o trajeto até o complexo esportivo [Maracanã] poderá ser feito desde a Zona Sul, passando pelo Centro, sem que se passe ao lado de favelas dominadas por traficantes. (Jornal O Globo, 2011, p. 12)

O fato é corroborado pelo jornalista esportivo (radialista) Luiz Ribeiro, que num programa dominical de esportes ancorado por ele e apresentado na Super-Rádio Tupi do Rio de Janeiro, afirmou que “[...] está sendo construído um corredor de segurança entre o Maracanã e o Engenhão, em razão da Olimpíada de 2016". (Rádio Tupi-AM, dia 29 de maio de 2011, programa "Bola em Jogo", horário de 12 até 15 horas)

Malgrado as inúmeras ocorrências na imprensa informando que a instalação da UPP do morro da Mangueira completaria o cinturão de segurança para os megaeventos, após esse fato, governo e imprensa emudeceram-se no que se refere à relação entre vigilância e controle de favelas e ações governamentais voltadas para os megaeventos.

Para além desse silêncio, num período relativamente recente, o Secretário Beltrame fez declaração, em entrevista à BBC Brasil, afirmando que as UPPs não foram concebidas para os megaeventos e sim para a sociedade, negando, portanto, peremptoriamente, a relação entre UPPs e megaeventos. Segue excerto:

BBC Brasil - As UPPs são comumente associadas aos megaeventos que o Brasil vai sediar até 2016, e isso acaba falando de dois temores que a sociedade tem em relação a esse projeto: o medo de as UPPs valerem apenas até 2016 e também de se limitarem ao território onde os jogos vão ocorrer.

Beltrame - Mas não há fundamento nisso, porque o projeto de UPP vê quarenta grandes complexos e no momento em que terminarmos esse projeto os níveis de criminalidade no Rio certamente estarão em outro patamar. Já estão hoje, com apenas 19 (UPPs instaladas).

Obviamente as coisas não são feitas para os eventos, são feitas para a sociedade. Não podemos fazer todo um trabalho desses, com uma proposta estruturante, para realizar o evento, tem que ser para atender a população ${ }^{2}$. (BBC, Brasil, 2012, grifos nossos) 


\section{Relação Megaeventos e UPPs: representações das favelas na cidade}

Conforme fora argumentado, procurou-se fundamentar esta pesquisa com fontes de natureza distintas, cotejando-as, a fala do governo, por meio do que foi divulgado na imprensa, no início da implantação das UPPs, não estabeleceu explicitamente uma relação e entre o modelo de policiamento colocado em prática pelas UPPs e os megaeventos. No entanto, conforme argumentado com o auxílio do Dossiê da candidatura do Rio de Janeiro aos Jogos Olímpicos e Paraolímpicos de 2016, nota-se que essa relação é possível de ser feita, utilizando-se uma fonte pouco discutida tanto na imprensa como na literatura científica. As menções aos megaeventos a partir da implantação das UPPs, ainda que não diretamente relacionasse às finalidades do programa aos grandes eventos, passaram a ficar transparente, de acordo com exposição que fiz, quando da preparação para a UPP da Mangueira, embora tal relação tenha sido logo após esquecida e silenciada por parte do governo e da imprensa.

Portanto, cruzando as declarações oficiais do governo acerca dos objetivos das UPPs com a proposta de segurança que figura no Dossiê, sugere-se a ligação entre o fato de o Rio de Janeiro ser uma cidade que vai sediar megaeventos e a implantação das UPPs como um dos objetivos não claramente declarados do projeto de policiamento de favelas, o que nos leva a pensar nesse programa não apenas como algo que carrega em si certo grau de inovação, mas que também revela uma faceta de continuidade no tratamento do "problema da favela" (Machado da Silva, 2002), bem como da "metáfora da guerra" (Leite, 2000), vinculando, imprecisamente, favelas e problemas urbanos ligados à violência, tornando problemático o lugar delas na cidade.

Há, portanto, uma questão que continuamente pulsa e incomoda deveras: por que a relação megaventos/UPP, já deslindada, não é abertamente tratada como um objetivo das UPPs ou, pelo menos, como um dos vetores que orientam o programa? Ora, se o projeto foi sendo construído, segundo Beltrame, como “[...] um laboratório, um modelo de política de segurança pública [...]" (Jornal O Globo, 2008, p. 13), e se este modelo implantado condiz com o que foi proposto no Dossiê da 
candidatura do Rio de Janeiro aos Jogos Olímpicos e Paraolímpicos de 2006, texto este publicado em 2009 e que certamente foi produzido no decorrer de 2008, antes da implantação das UPPs, por que não admitir com franqueza que se trata de uma política pública impulsionada também (não exclusivamente, talvez) em razão dos megaeventos?

Muitas podem ser as explicações possíveis para dar conta dessa pergunta. É possível acionar explicações políticas acerca da natureza do trabalho da imprensa etc. Ressalta-se uma pista para a resposta, caminho esse sedimentado pela literatura científica sobre a história das favelas, pois as representações das favelas na cidade do Rio de Janeiro emergiram, desenvolveram-se e constituíram-se como um problema da ordem da marginalidade e das "classes perigosas", isto é, como uma disfunção no corpo social que gerou, no campo da percepção social, "células problemáticas". Logo, conclui-se que há ainda uma permanência histórica no que se refere às representações das favelas e dos favelados como um problema para a cidade tanto no tocante à ordem territorial como ligado à violência e às representações dos seus moradores, fato que conduz Estado e entidades paraestatais a agirem nas favelas, não raramente, referenciados em operações simbólicas negativas, pejorativas, o que gera políticas de vigilância e controle das favelas. (Leite, 2000; Machado DA Silva, 2002; Perlman, 1977; Valladares, 2000)

Dessa forma, a vigilância e o controle (Foucault, 2011) que regeram historicamente a relação entre Estado e favelas, bem como instituições paraestatais e favelas, parecem incrustarem-se como elementos de continuidade do programa das UPPs, na medida em que não declaradamente o programa conserva relação com os megaeventos, acionando, implícita ou explicitamente, as representações das favelas como um iminente perigo social a ser vigiado e dirigido, pois sem isso os eventos poderiam estar ameaçados. Nesse sentido, segundo Machado da Silva (2010, p. 7, grifos nossos):

[...] há uma modalidade mais afirmativa de resistência, que me parece muito associada aos segmentos mais esclarecidos das camadas populares. Ela diz respeito a uma crítica de fundo, focada no significado que pode ter a noção de "ordem pública" que nortearia não apenas a prática, mas a 
própria filosofia que organiza o programa das UPPs. É uma reação que denuncia o caráter unilateral da definição e os critérios de sua implementação pelos policiais. Repudia o que considera, até certo ponto com razão, implícito na atuação concreta das UPPs: a tentativa de regular a vida cotidiana local segundo padróes de conduta fortemente invasivos da privacidade dos moradores, verdadeiros substitutos das garantias dos direitos civis que se espera dos responsáveis diretos pela ordem pública.

O que foi colocado em discussão baseia-se numa relação possível de ser percebida entre os megaeventos e as UPPs, muito embora essa ligação tenha sido muito moderadamente colocada em pauta. Isso nos conduz a pensar essa relação com base em dois pontos: (i) a continuidade das representações das favelas como lugares disfuncionais e o estigma de seus moradores orienta a proposição de um programa que visa vigiar, controlar e gerir essa população, pois ela engendra uma noção de perigo para os megaeventos (e para cidade) (Foucault, 2008); (ii) não só controle e gestão são importantes nesta relação, mas, a partir da vigilância e do controle, gerar a produção de indivíduos em conformidade com o bom adestramento e, para tanto, o olhar de perto de um modelo de policiamento não eliminaria somente o perigo de bandidos, mas forjaria também, por meio da verificação diária das condutas das pessoas, cidadãos de acordo com os objetivos governamentais, pois conforme Foucault:

O sucesso do poder disciplinar se deve sem dúvida ao uso de instrumentos simples: o olhar hierárquico, a sanção normalizadora e sua combinação num procedimento que lhe é específico, o exame. (Foucalt, 2011, p. 164)

\section{Considerações Finais}

É importante deixar transparente que não se visou, neste artigo, discutir diretamente se o projeto das UPPs é bom ou ruim, muito menos se vai ter continuidade ou não após os megaeventos, muito embora as críticas não possam ser negadas. Também não teve interesse o fato de o programa ser ou não referendado pelos moradores de favelas ou por 
não moradores. Não obstante todas essas questões pontuadas sejam relevantes, elas não figuraram como escopo deste trabalho, pois o foco essencial foi deslindar e expor o projeto das UPPs para além de sua perspectiva patentemente divulgada e propalada.

O mérito da questão que foi colocado em perspectiva crítica foi considerar o programa das UPPs no seu sentido da dimensão de sua continuidade como intervenção nas favelas cariocas e relação entre estes lugares de moradia e o poder público. Embora o referido projeto de policiamento represente - ao menos em suas propostas - mudanças e inovações, objetivei mostrar em que medida ele conserva uma continuidade relacionada à vigilância e controle das favelas, sendo importante destacar, neste ponto, que há uma lógica que parte da consideração das favelas como lugares que produzem pessoas perigosas, que carregam uma "essência" que é estigmatizada. Nesse sentido, o projeto também opera com modelos de conduta que são corolários da vigilância e controle impostos. (Foucault, 2002; Foucault, 2011)

Esse foi o intento do esforço de pesquisa feito: procurar transcender os limites discursivos e informativos dados pelo Estado e pela imprensa de modo geral. A partir desse esforço crítico, recorri a declarações oficiais que deixaram patentes o escopo do projeto das UPPs, para, em seguida, colocar como contraponto os objetivos que não estão dados, oferecidos e nem visibilizados, conforme exposto no Dossiê da Candidatura do Rio de Janeiro à Olimpíada e Paraolimpíada de 2016.

Com base nos argumentos construídos, procurou-se enfrentar, finalmente, uma questão fundamental, ligada à omissão da relação entre UPPs e megaeventos, sugerindo como matriz explicativa que o elemento de continuidade inerente ao programa das UPPs, vigilância e controle das populações consideradas "perigosas", pode ser perseguido tendo como fio condutor as representações das favelas como uma disfunção no que se refere às cidades, bem como dos seus moradores como "problema" na cidade.

Diante de toda a construção feita, vale encerrar o artigo explicitando e colocando em evidência uma questão que considero fundamental nos estudos sobre políticas públicas dirigidas às populações subalternas ou em condição de marginalidade: ações em favelas devem 
ser pensadas a partir de novas representações destes lugares e de seus moradores na cidade.

\section{Notas:}

1 Doutorando do Programa de Pós-Graduação em Ciências Sociais (PPCIS) da Universidade do Estado do Rio de Janeiro (UERJ), com bolsa de pesquisa financiada pela Capes. Mestre em História Social (UERJ). Especialista em Sociologia Urbana (UERJ). Bacharelado e licenciatura em História pela Universidade Gama Filho (UGF).

2 Não há a data precisa da entrevista no Site, mas há a data da atualização, que foi feita em 15 de março de 2012.

\section{Referências}

BBC Brasil, Júlia Dias Carneiro - enviada especial da BBC Brasil a Doha. Atualizado em 15 de março, 2012 - 05:41 (Brasília). "Hoje a UPP está nas mãos da sociedade", diz Beltrame. [2012]. Disponível em: < http://www.bbc. co.uk/portuguese/noticias/2012/03/120314_beltrame_doha_jc.shtml >. Acesso em: 19 dez. 2012.

BIRMAN, Patrícia. "Favela é comunidade?". In: MACHADO DA SILVA, Luiz Antonio (Org.). Vida sob cerco: violência e rotina nas favelas do Rio de Janeiro. Rio de Janeiro: Nova Fronteira, 2008. p. 97-114.

BECKER, Howard C. Outsiders: estudos de sociologia do desvio. Jorge Zahar, 2008. p. 15-30.

BURGOS, Marcelo Baumann. 1998. Dos parques proletários: as políticas públicas nas favelas do Rio de Janeiro. In: ZALUAR, Alba; ALVITO, Marcos (Org.). Um século de favela. Rio de Janeiro, FGV. p. 25-60.

CARVALHO, Maria Alice Rezende de. Violência no Rio de Janeiro: uma reflexão política. In: PEREIRA, C. Alberto Messeder et al. (Org.). Linguagens da Violência. Rio de Janeiro: Rocco, 2000. p. 47-74.

COMITÊ OLÍMPICO BRASILEIRO. Dossiê de Candidatura do Rio de Janeiro à Sede dos Jogos Olímpicos e Paraolímpicos de 2016. Rio de Janeiro: COB, 2009. 3 v.

FOUCAULT, M. A História da sexualidade I: a vontade de saber. Tradução Maria Thereza da Costa Albuquerque e J. A. Guilhon Albuquerque. Rio de Janeiro: Ediçõos Graal, 1988. (22ª impressão)

. Em defesa da sociedade. Tradução Maria Ermantina Galvão. São

Paulo: Martins Fontes, 1999. (Coleção Tópicos) 
. A verdade e as formas jurídicas. Tradução Roberto Cabral de Melo Machado e Eduardo Jardim Morais, supervisão final do texto Léa Porto de Abreu Novaes et al.). Rio de Janeiro: NAU Editora, 2002a.

. Os anormais. São Paulo: Martins Fontes, 2002b.

. Segurança, território e populações: curso dado no Còllege de France (1977/1978). São Paulo: Martins Fontes, 2008. 2011.

. Vigiar e punir: nascimento da prisão. 39. ed. Petrópolis, RJ: Vozes,

. O uso dos prazeres e as técnicas de si. In: Ditos e escritos, volume V: ética, sexualidade, política. 3. ed. Rio de Janeiro: Forense Universitária, 2012a. p. 187-211.

A vida dos homens infames. In: Ditos e escritos, volume V: ética, sexualidade, política. 3. ed. Rio de Janeiro: Forense Universitária, 2012b. p. 203-222.

JORNAL O GLOBO, sexta-feira, 3 de dezembro de 2008, . sexta-feira, 28 de novembro de 2008. . terça-feira, 31 de maio, Ano LXXXVI, n. 28.421, 2011.

JORNAL O DIA, 2 de maio, Ano 59, número 21.137, 2. ed., 2010.

Disponível em: < http://odia.ig.com.br/portal/rio/beltrame-oalem\%C3\%A3o-e-a-penha-ter\%C3\%A3o-2-mil-homens-s\%C3\%B3-nasupps-1.125716>. Acesso em: 29 out. 2013.

. Ano 60, n. 21.529, terça-feira, 31 de maio, 1. ed., 2010.

JORNAL EXPRESSO, terça-feira, 31 de maio, Ano VI, n. 1.684, 2011.

LEEDS, Anthony; LEEDS, Elizabeth. A sociologia do Brasil urbano. Rio de Janeiro, Zahar, 1978.

LEITE, Márcia Pereira. Entre o individualismo e a solidariedade: dilemas da política e da solidariedade no Rio de Janeiro. Revista Brasileira de Ciências Sociais, v. 15, n. 44, p. 73-90, outubro de 2000.

. UPPs, uma unanimidade? Jornal O Fluminense, suplemento dominical, publicado em dezembro de 2010.

PARISSE, Luciano. Favelas do Rio de Janeiro: evolução e sentido. Rio de Janeiro: Centro Nacional de Pesquisas Habitacionais - CENPHA, 1969.

RABINOW, P.; DREYFUS, H. O Sujeito e o poder: a natureza do entendimento antropológico. In: Michel Foucault: uma trajetória filosófica para além do estruturalismo e da hermenêutica. Rio de Janeiro: Forense, 1995. p. 231-249. 
RÁDIO TUPI-AM, dia 29 de maio de 2011, programa "Bola em Jogo", horário de 12 até 15 horas.

RIBEIRO, Luiz César de Queiroz; SANTOS JÚNIOR, Orlando Alves. Desafios da questão urbana. In: Le Monde Diplomatique Brasil, p. 4-5, abril 2011.

RONDELLI, Elizabeth. Imagens da violência e práticas discursivas. In: PEREIRA, C. Alberto Messeder et al. (Org.). Linguagens da violência. Rio de Janeiro: Rocco, 2000. p. 144-162.

SILVA, Maria Lais Pereira da. Favelas cariocas: 1930-1964. Rio de Janeiro: Contraponto, 2005.

ACHADO DA SILVA, L. A. A política na favela. Cadernos Brasileiros, Rio de Janeiro, v. 9, n. 3, maio-jun. p. 35-47, 1967.

. A continuidade do 'problema favela. In: OLIVEIRA, Lucia Lippi (Org.).

Cidade: história e desafios. Rio de Janeiro: Editora FGV, 2002. p. 220-237.

. Afinal, qual é a das UPPs?. [2010]. Disponível em: <www.

observatoriodasmetropoles.ufrj.br>. Acesso em: $1^{\circ}$ mar. 2010.

MENDONÇA, Sonia R. Estado e economia no Brasil: opções de desenvolvimento. Rio de Janeiro: Graal, 1986.

PERLMAN, J. E. O mito da marginalidade: favelas e política no Rio de Janeiro. Rio de Janeiro: Paz e Terra, 1977.

VALLA, Victor Vincent. (Org.). Educação e favela. Petrópolis: Editora Vozes, 1986. VALLADARES, Lícia do Prado. A gênese da favela carioca. Revista Brasileira de Ciências Sociais, São Paulo, v. 15, n. 44, outubro, 2000.

VALLADARES, Lícia do Prado; PRETECEILLE, Edmond. A Desigualdade entre os Pobres - favela, favelas. In: HENRIQUES, Ricardo. (Org.).

Desigualdade e pobreza no Brasil. Rio de Janeiro: IPEA (Instituto de Pesquisa Econômica Aplicada), 2000. p. 459-485.

. A Invenção da favela: do mito de origem a favela.com. Rio de Janeiro: Editora FGV, 2005.

ZALUAR, Alba; ALVITO, Marcos (Org.). Um século de favela. Rio de Janeiro: FGV, 1998.

Recebido em 26/04/2013

Aceito em 03/06/2013 